\title{
Repeated drop weight impacts and post-impact ILSS tests on glass-epoxy composite
}

\author{
KISHORE*, S RAMANATHAN ' and R M V G K RAO ${ }^{++}$ \\ Centre for Advanced Study. Department of Metallurgy. Indian Institute of Science. Bangalore \\ 560012 India \\ Wipro Systems Ltd., Bangalore 560001 , India \\ Materials Division. National Acrospace I aboratorics. Bangalore 560017. India \\ MS received 5 February 1996: revised 17 September 1996
}

\begin{abstract}
E glass epoxy laminates of thick nesses in the range $2-5 \mathrm{~mm}$ were subjected to repeated impacts. For each thickness the number of hits to cause tup penetration was determined and the value of this number wats higher the larger the thickness of the laminate tested. The C-scan, before and after impact, was done to obtain information regarding flaw distribution. Short beam shear test samples wore made from locations at fixed distances from impact point and tested. The samples cleser to the zone of impact showed lower strength values. Scanning fractography revealed shear deformation features for these samples and brittle fracture features for the region near the zone of impact.
\end{abstract}

Keywords. Glass-epoxy: impacts: post-impact interlaminar shear strength: fractography.

\section{Introduction}

The assessment of damage, introduced either during processing stage or during subsequent use as a structural component, and concomitant property degradation in laminated composite materials has gained importance in recent years. Properties generally evaluated to establish the post damage performance include tensile, compressive and flexural ones (Chaturvedi and Sierakowski 1985; Cantwell et al 1986; Challenger 1986; Dorey 1989; Prichard and Hogg 1990: Kim et al 1993; Ujihashi 199j; Hull and Shi 1994). For introducing the damage in the test piece usually impacting the laminate at low velocity/low energy is resorted to. As a consequence of such impacts matrix cracking, delamination, breakage of fibrous reinforcement and the like features appear in the impacted material. The thick ness of the laminate, velocity and energy of impact. fibre and resin content, interfacial adhesion, test specimen mounting etc are some of the parameters that have a bearing on the results derived. Damages due to impact are most felt at the region of impact. The area around the impact point also show the introduction of flaws due to impact and this region of influence is governed by factors like velocity/energy and whether the process is one time operation or repeated many times.

Repeated impacts or impact fatigue (Takemori 1982; Wyrick and Adams 1988; Jang et al 1991, 1992), where the same point of the structural composite laminate is subjected to impacts over and over, using preferably the same mass of impactor dropped from fixed height, in order to keep the velocity and energy parameters constant, is simple and effective method to gain an insight into the subject of impact induced damage. The residual mechanical properties, after impact. are determined to correlate the strength vis-a-vis the extent of damage.

\footnotetext{
*For correspondence
} 
In this study a commercial unit is made use of to repeatedly impact a E glass-epoxy compression moulded laminate and record the number of impacts necessary to cause the tup penetration. The zone of impact as well as the post impact mechanically tested and failed samples were scanned in a scanning electron microscope (SEM) for characterizing the fracture surface details. Prior to doing microscopic examination the sample was examined both before and after impact to get an outline of inhomogeneities and thus assess the impact induced defect level. Some macroscopy using light microscope was also done to get details in and around the zone of impact. With tup penetration as a reference parameter how thickness variation affects the repeated impact data for smaller sized test samples and building a correlation among microstructure, defect level, mechanical strength values and failure features are the two main aspects investigated and reported in this work.

\section{Materials and methods}

Epoxy compatible E-glass ( 8 harness, 8 mil) satin weave cloth and the commercially available LY 556 epoxy resin (diglycidyl ether of bisphenol-A) manufactured by Hindustan Ciba Geigy Ltd., Bombay, constituted respectively the reinforcement and the matrix material. The hardener employed was a room temperature curing hexamethyl diamino diphenyl sulphone, with a trade name of HY951.

The resin and the curing agent were thoroughly mixed and layup sequence, on a cleaned and prepared steel mould plate, involving the glass cloth (cut to the required size) and resin mixture begun. The procedure was stopped when all the reinforcement material (as dictated by the thickness to be made) was used up. A top layer followed by mould plate was placed on the layup and the entire assembly subjected to compression moulding. The excess resin was allowed to be squeezed out. Placement of metal spacers assisted in the procurement of laminates of required thickness.

The laminates were cured at room temperature for $24 \mathrm{~h}$. The operation standardized to yield laminates of consistent quality and glass content of about 0.5 by volume fraction for the various thicknesses prepared in this work. The composites were then cut to yield impact test samples. The cured laminates were subjected to $\mathrm{C}$-scan probing to ensure the quality of the laminate is consistently uniform for further use. This way it was ensured that whatever damage that occurred in a significant measure was principally due to the impact of the drop weight. To estimate the actual resin content in the prepared laminate a standard burnout test was conducted.

For the instrumented impact test, a commercial Dynatup testing machine (model 8250 ) was used. The mass and the diameter of the tup used were respectively $2.5 \mathrm{~kg}$ and $12 \mathrm{~mm}$. The unit had an electronic control for clamping and releasing the tup. A winch helps in raising and lowering the weight to the required height which in the present case was kept at $78.5 \mathrm{~cm}$. The strike velocity was of the order of $3.94 \mathrm{~m} / \mathrm{s}$. Positioning at the required height helped in getting the same impacting condition.

A smaller $4 " \times 4^{\prime \prime}$ sized impact sample (instead of the usual larger size) was prepared and the same examined by the non destructive (ND) technique following which the ( $2 \mathrm{~mm}$ thick) test sample was subjected to repeated impacts using an indigenously designed and fabricated fixture having a circular opening and mounted on to the unit. The repeated impacts were done till the tup penetrated the laminate. The number of drops for such a penetration for a given thickness was noted. The same exercise was 
repeated for the thicker laminates also. Following the occurrence of the tup penetration stage, the defects introduced in the composite system due to the impacts were examined using the C-scan technique and the features around the central zone of penetration photographed utilizing the attenuation (Raghunath and David 1983) phenomenon. For the ND studies, a beam of energy (generated by the transmitter probe on one side of the composite) passing through the test piece was detected on the other side by the receiver probe using water as a coupling agent. The amount of energy detected by the receiver probe was affected by the quality of the composite through which it passed. Voids, porosity etc reduce the amount of transmitted energy. Using this and certain other in built accessories like a motorized rig and a computer the point by point data files for the $\mathrm{X}$ and $\mathrm{Y}$ coordinates were generated and stored. The computer system generated pictures of the test item with the digitized ultrasonic transmission values converted into colour bands.

The two faces of the laminate. viz. the bottom side and the top impacting (entry) side were examined in a light microscope in order to observe the impacted and surrounding regions by macroscopy. The bottom side was chosen for comparing by macroscopy the extent of the spread of the damage once the tup penetrated the test laminate. The salient features were photographed.

Following the macroscopy, on the impact tested laminates, specified distances, viz. $2 \mathrm{~cm}$ and $4 \mathrm{~cm}$, respectively, on either side of the centre of the central zone, were marked out. These marked out points formed the centre of the short beam shear test samples. The interlaminar shear strength (ILSS) samples cut from such regions had the span to depth ratio of 5:1 (ASTM 1989). Two sets of samples were thus obtained from either side of the central zone along the diagonal of the square test specimens. To test the ILSS, a specially fabricated fixture having an adjustable specimen support on either side was used. In this fixture the span of the specimen support can be adjusted to the required value. The specimen, supported at two ends with a total length: depth of 7:1, was subjected to three point flexural loading (Saratchandra et al 1991; Matheswaran et al 1995; Padmanabhan and Kishore 1995) using a $100 \mathrm{kN}$ servo hydraulic Instron testing machine (model 8032). The shear strength was obtained from the load displacement curves. Apart from the impacted sample, the unimpacted laminates were also tested for the determination of ILSS value and subsequently used as reference for evaluating the fraction of strength retention as well as comparative strength changes due to repeated impacts.

The samples that failed in the ILSS tests and a small sectioned portion of the zone of the impact were examined under a JEOL make SEM. Before performing the microscopic examination for studying the fractographic details, the samples had to be coated with a conducting layer using a sputtering unit (Kaushal and Kishore 1992). From the 2,3 and $5 \mathrm{~mm}$ thick laminates the results obtained on any two set of samples are presented in order to highlight the effect of thickness on the test data.

\section{Results and discussion}

Figure 1 shows the number of impacts necessary to cause the tup penetration against the thicknesses employed for the same energy imparted at each impact (19-4J). It is clear that the $2 \mathrm{~mm}$ sample shows a complete penetration after the second impact itself. whereas this exercise when repeated with the thickest one $(5 \mathrm{~mm})$ shows such tendency 
after 36 impacts (figure 1). The laminates with in-between thickness i.e. $3 \mathrm{~mm}$, show penetration after 4 impacts. This behaviour is along expected lines and hence validates the usability of smaller sized sample (with the fixture) for a comparative evaluation work. In the data (figure 1) is included the test result obtained on a $4 \mathrm{~mm}$ thick sample. This thickness was specifically made for the impact experiments in order to have a comprehensive picture of the thickness effect.

Coming to the optical macrographs, figures 2 and 3 depict, respectively, the features on the bottom side for the $2 \mathrm{~mm}$ and $5 \mathrm{~mm}$ thick samples. A close observation of the photomicrograph reveals besides the central rupture a bright envelope. Surrounding

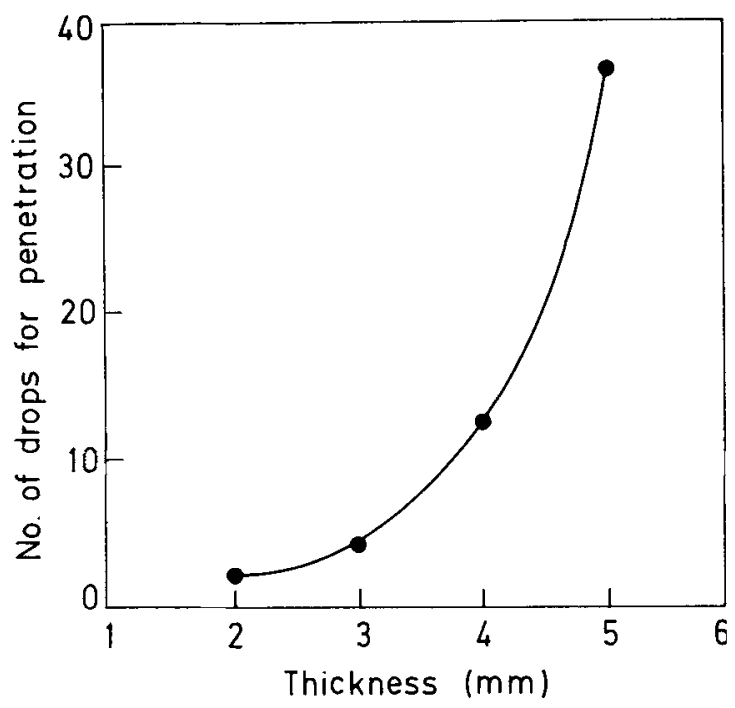

Figure 1. A plot describing the number of impacts to cause tup penctration for the different thicknesses of the laminate.

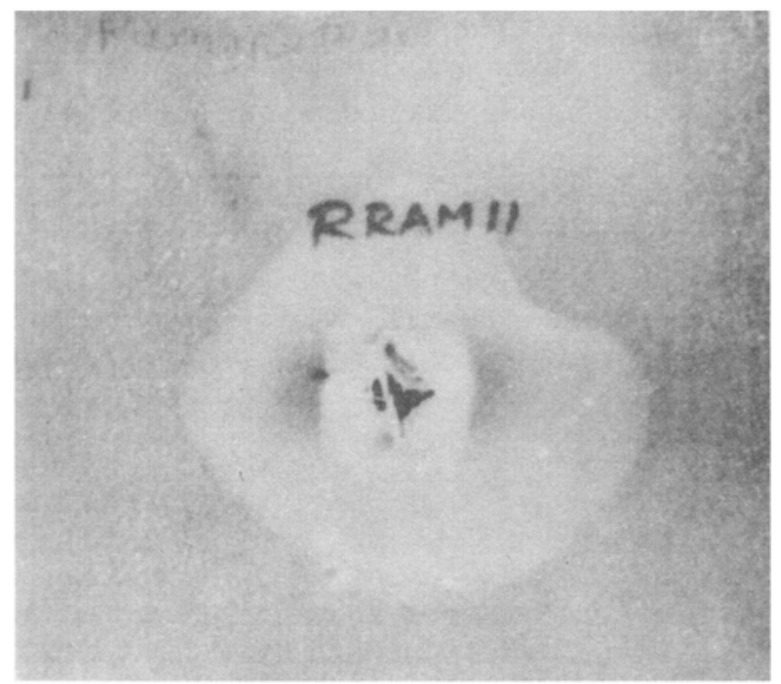

Figure 2. Light macroscopy of impacted zone in a $2 \mathrm{~mm}$ thick specimen $(\times 0.8)$. 


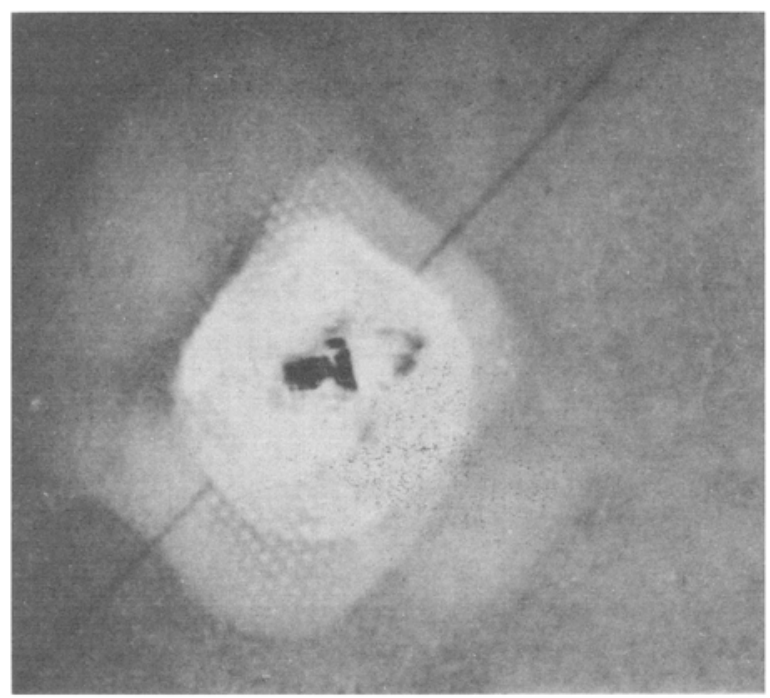

Figure 3. Light macroscopy of impacted zone in a $5 \mathrm{~mm}$ thick sample $(\times 1.5)$.

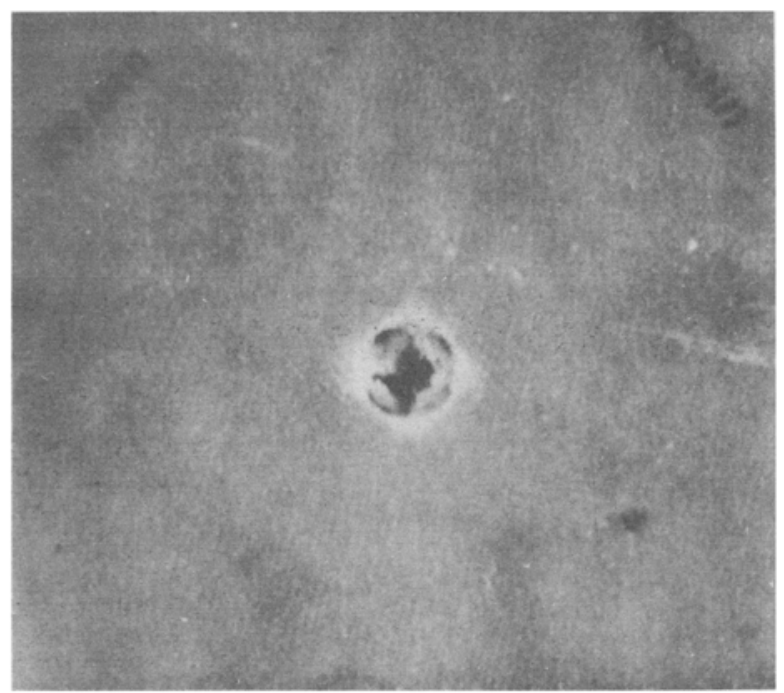

Figure 4. The features on the top (entry) side of the $2 \mathrm{~mm}$ laminate $(\times 0.8)$.

this bright zone is a well marked grey area with a distinct boundary. The different areas reflect variously the many fracture features such as fibre breakage, brooming out of fibres, fibre matrix interface decohesion, delamination, matrix cracking etc occurring to varying degree. Figure 4 brings out for a $2 \mathrm{~mm}$ sample the difference in appearance on the (tup) entry side compared to the bottom side (figure 2).

The well defined but larger grey layer area in the thinner test sample (figure 2) can be ascribed to greater degree of spread of the damaged area. The C-scan pictures for thinner sample (figure 5) as compared to the thicker one (figure 6) show greater 


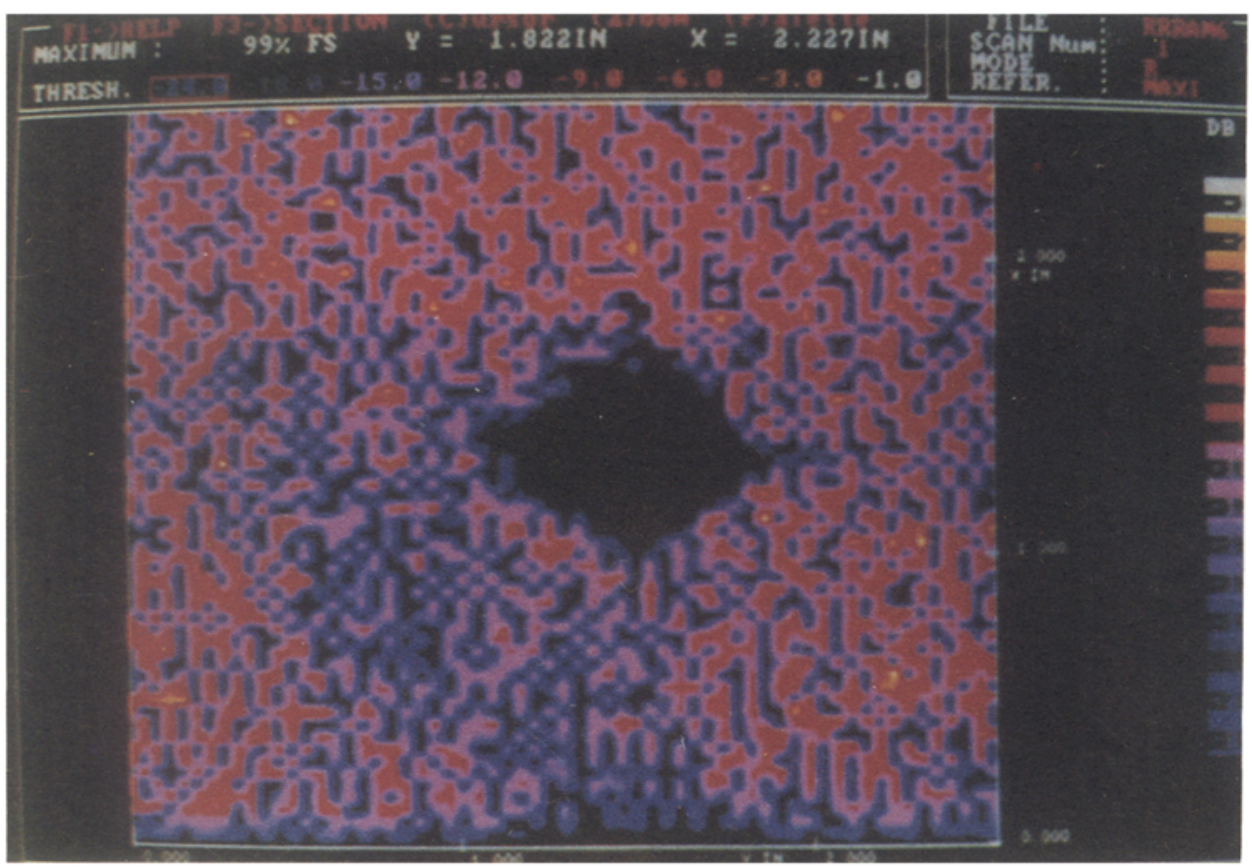

Figure 5. The $\mathrm{C}$-scan picture of a $3 \mathrm{~mm}$ sample.

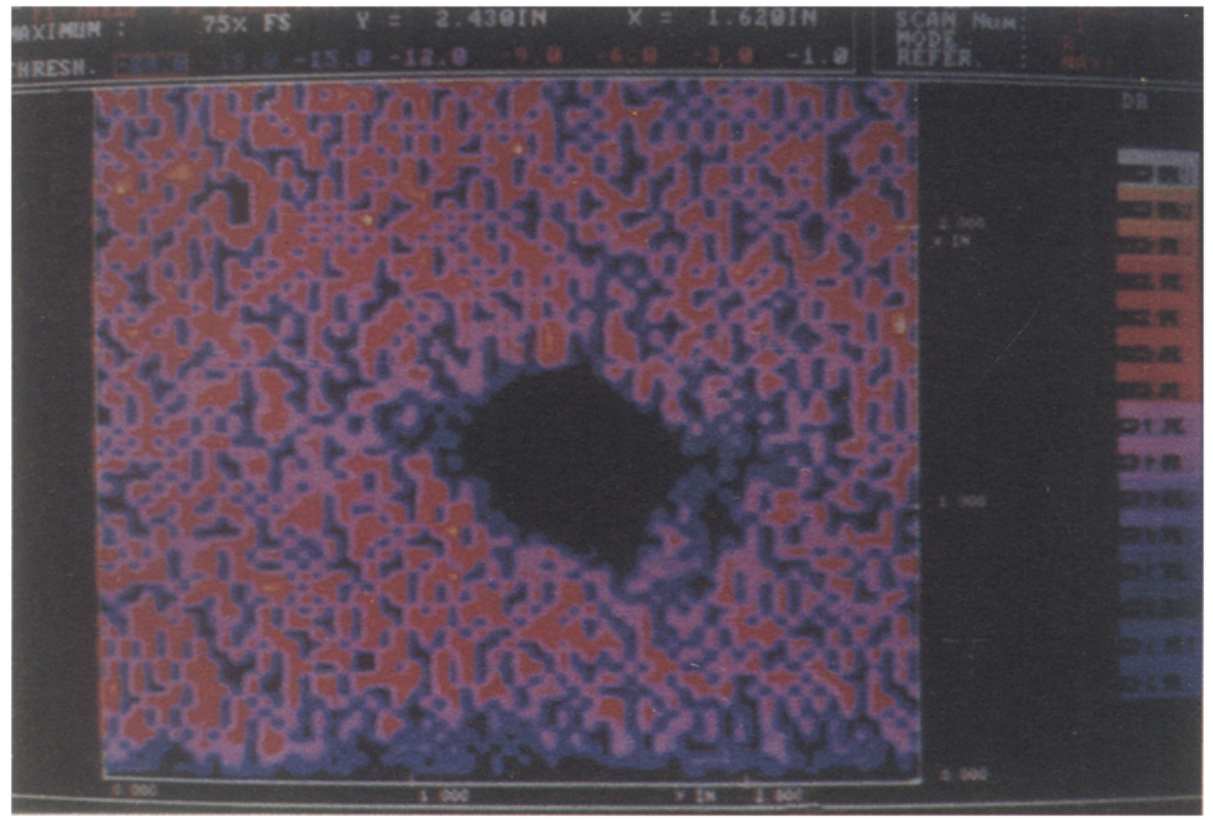

Figure 6. The $\mathrm{C}$-scan picture of a $5 \mathrm{~mm}$ sample. 
Table 1. Strength retention data for 2 and $3 \mathrm{~mm}$ thick laminates at two distances from impact point.

Distance (cm) from
impact porm
Fraction $\because$
of strength
retained in

$\mathrm{a}=2 \mathrm{~mm} ; \mathrm{b}=3 \mathrm{~mm}$

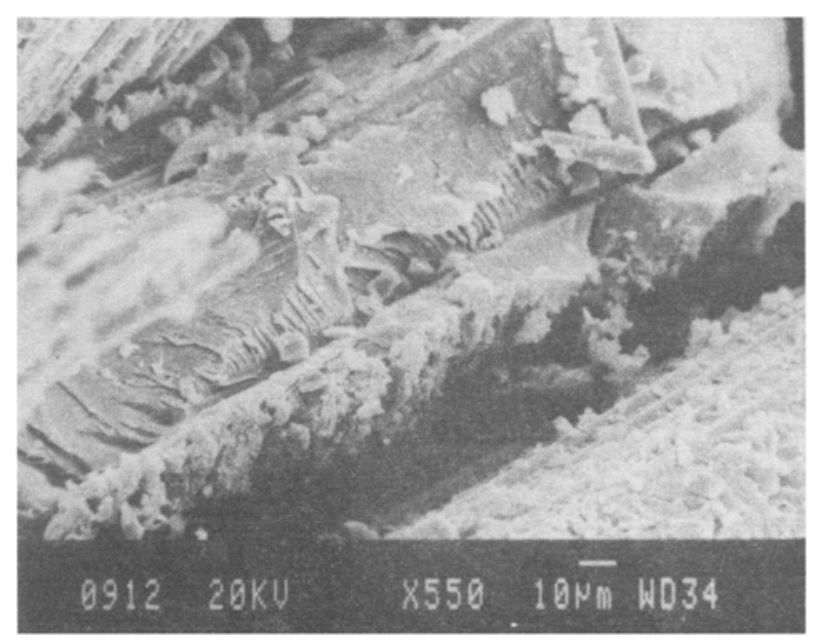

Figure 7. Fractography teaturing britte tailure features.

attenuation. representing the regions of laminar type debonds in the former especially around the central point and this observation agrees with the light macroscopic data. Regions of less delaminations and disbond bearing material surround the area around the core cent ral zone. while the less weakly bonded and more homogeneous material appears to be in greater proportions at regions away from the impact zone.

With the interlaminar shear strength of unimpacted test sample as a reference value the changes in the fraction of strength retained lobtained by dividing the values of impacted sample with respect o unimpacted ones) for $2 \mathrm{~mm}$ and $3 \mathrm{~mm}$ for fixed distances from central impact point are shown in table 1 . The larger drop at around the central zone for both the thicknesses (i.c. $2 \mathrm{~mm}$ and $3 \mathrm{~mm}$ ) shows that mechanical test data are in complete agreement with the light macroscope and NDE results. In other words a correlation amongst defect level (laminate quality). macroscopy, and mechanical test values could be obtained from this study,

On extending this work to a detailed fractography using SEM it is seen that the central zone (figure 7) reveals broken libres, river patterns, cleavage of matrix, all indicative of brittle fractures. This region receiving repetitive impacts shows typical fast fracture 


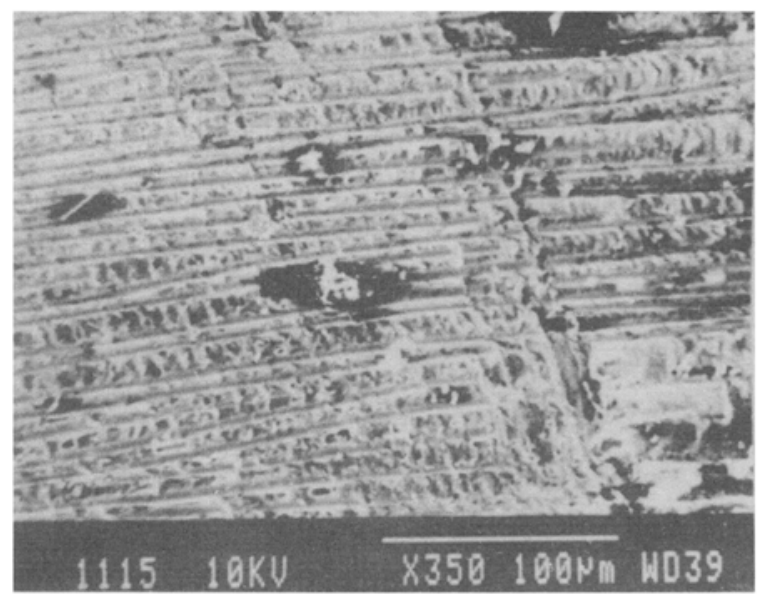

Figure 8. Shear cusps noticed in samples failed in three point loading (ILSS) tests.

failure features expected in a laminated composite. On the other hand, sample failing in a 3-point bend test, performed to yield information on ILSS, shows typical shear cusps (Samajdar and Kishore 1991) seen in epoxy matrix (figure 8). The test involving shear clearly highlights the matrix participation in the deformation process. To summarize the structure property correlation emphasized earlier can be extended to electron fractography part also. However, before closing, the significance of energy absorbed due to impacts and related parameters need to be looked into for seeking a more comprehensive picture as regards the role of thickness of laminate in impact experiments.

\section{Conclusions}

From the investigations the following points emerge: smaller sized impact samples along with interlaminar shear strength determination tests can be used to assess the post-impact strength retention abilities especially for the thinner samples. The tup penetration situation requires larger number of impacts for the thicker samples. Macroscopy is an useful tool to make a broad assessment of flaw distribution whereas C-scan studies yield information on the laminar type defects. Samples from closer to the impact zone yield lower strength and exhibit shear deformation features. Brittle fracture features like river patterns, fibre breakage etc are distinctly noticed in the zone of impact. The data derived from macroscopy, non destructive evaluation, mechanical tests and fractography could be successfully correlated.

\section{Acknowledgements}

The authors would like to place on record the assistance rendered by the staff at the Department of Metallurgy, Indian Institute of Science and the Materials Division, National Aerospace Laboratories, Bangalore. The first author (Kishore) greatly appreciates the willing co-operation of Prof. C R L Murthy, Department of Aerospace Engineering, IISc., Bangalore. He also would like to thank the members of his Polymer Matrix 
Composites Group for the enthusiastic assistance. The second author (SR) would like to thank his friends and colleagues for the assistance rendered. The Chairman, Department of Metallurgy, IISc., is thanked for the facilities extended for the successful completion of this investigation. The keen interest shown by the Head, Materials Division and Director, National Aerospace Laboratories is greatly appreciated.

\section{References}

ASTM 1989 STP D 2344-84

Cantwell W J, Curtis P T and Mortan J 1986 Comp. Sci.\& Tech. 25133

Challenger K D 1986 Comp. Struct. 6295

Chaturvedi S K and Sierakowski R L 1985 J. Comp. Matls. 19100

Dorey G 1989 Damage tolerance and damage assessment in advanced composites, in Adranced composites (ed.) I K Patridge (London: Elsevier Applied Science) p. 369

Hull D and Shi Y B 1994 Comp. Strucl. 2399

Jang B P. Huang C T. Hsieh C Y. Kowbel W and Jang B Z. 1991 J. Comp. Matls. 22749

Jang B P. Kowbel W and Jang B Z 1992 Comp. Sci. \& Tech. 44107

Kim J K, Mackay D B and Mai Y W 1993 Composites 24485

Kaushal S and Kishore 1992 J. Mutls. Si. Lett. 1186

Matheswaran M, Padmanabhan K and Kishore 1995 J. Matls. Sic. Lett 14951

Padmanabhan K and Kishore 1995 Mits. Sir. \& Fingy. A197113

Prichard J C and Hogg P J 1990 Composites 21503

Raghunath P K and David C C 1983 J. Comp. Matls. 17182

Samajdar S and Kishore 1991 J. Matls. Sit. 26977

Saratchandra D. Avadhani (; S and Kishore 1991 Scr. Mctall \& Mater. 251641

Takemori M T 1982 J. Matls. Sci. 17164

Ujihashi S 1993 Comp. Stru't. 23149

Wyrick D A and Adams D F $1988 J$. (mmp. Matk. 22 749 